\title{
Análise quantitativa e qualitativa da degradação das fachadas com revestimento cerâmico
}

\section{(Quantitative and qualitative analysis of deterioration of facades with ceramic external coating)}

\author{
C. P. Pacheco, G. L. Vieira \\ Programa de Pós-Graduação em Engenharia Civil, Centro Tecnológico, \\ Universidade Federal do Espírito Santo, Av. Fernando Ferrari 514, Vitória, ES, Brasil 29075-910 \\ clari1512@hotmail.com, geilma.vieira@gmail.com
}

\begin{abstract}
Resumo
Este artigo teve por objetivo mostrar a aplicação de uma metodologia para inspeção de fachadas em edifícios, baseada em modelos pré-estruturados. Foram vistoriados três prédios com revestimento externo em cerâmica, totalizando $4958 \mathrm{~m}^{2}$ de área de fachada inspecionada. Mediante a inspeção visual, realizou-se o levantamento das áreas das manifestações patológicas por região e orientação cardeal da fachada e definiram-se os níveis de degradação. Foram realizados testes de percussão nas fachadas e ensaios de absorção de água e expansão por umidade nas placas cerâmicas. Como complemento, levantaram-se as informações referentes aos edifícios por meio de entrevistas e análises de projetos. Foi elaborada a matriz de correlação anomalias versus causas, que permitiu avaliar a origem dos danos. As anomalias com maior ocorrência nos edifícios foram as manchas e sujeiras e a deterioração nos rejuntes. Constatou-se a influência da cor das cerâmicas e da posição das fachadas no desplacamento. Com base nos ensaios de absorção de água, verificou-se que dois edifícios apresentaram cerâmicas com alto índice de absorção e a análise das regiões de fachadas mostrou que a ausência de juntas foi uma das causas do desplacamento em paredes contínuas e na transição entre pavimentos.

Palavras-chave: manifestação patológica, revestimento externo, revestimento cerâmico, inspeção.
\end{abstract}

\begin{abstract}
This article aimed to show the application of a methodology for inspection of facades in buildings, based on pre-structured models. Three buildings with external ceramic coating were inspected, with the total inspected facade area of $4958 \mathrm{~m}^{2}$. By visual inspection, a survey of the areas of pathological manifestations by region and cardinal of the facade orientation was obtained, and the degradation levels were defined. Percussion test in the facades and water absorption and expansion by moisture tests in the ceramic plaques were performed. Relevant data concerning the buildings were obtained with interviews. The correlation matrix anomalies versus causes was elaborated, which allowed to assess the origin of the damage. Anomalies with greater occurrence in buildings were the stains and dirt and the deterioration in grouts. It was found the influence of the ceramic color and the position offacades on peeling. From the water absorption test, it was found that the ceramics of two buildings had high rate of absorption, and the analysis of facades regions showed that the absence of movement joints was one of the causes of peeling in the continuous walls and the transition between floors.
\end{abstract}

Keywords: pathological manifestations, external coating, ceramic tiles, inspection.

\section{INTRODUÇÃO}

Uma das funções do revestimento externo é proteger a edificação contra a ação de agentes agressivos [1]. Desta forma, o revestimento fica exposto a inúmeras solicitações deletérias, tais como variações térmicas, vento, umidade, ruído, chuva, incidência solar, carregamentos estático e dinâmico, impacto e peso próprio. Portanto, as fachadas das edificações, por estarem expostas às intempéries naturais, representam uma das áreas mais deterioradas ao longo do tempo [2]. Assim, é importante entender o funcionamento do revestimento externo e analisar as manifestações patológicas existentes nesses locais, a fim de aprimorar esse sistema e minimizar a ocorrência de problemas. As influências dessas ações deletérias levam à perda de desempenho do revestimento e, consequentemente, da sua durabilidade. Para minimizar esses impactos, são necessárias manutenções e inspeções periódicas, que têm a finalidade de detectar os problemas existentes, estudar as causas e avaliar o estado de deterioração do edifício. Para tanto, é importante garantir que essas inspeções ocorram de maneira adequada, levando em conta o histórico do edifício, para que seja possível entender o comportamento das fachadas e propor melhorias nos projetos, na execução, na utilização e na manutenção delas.

As principais incidências patológicas percebidas em fachadas com revestimento cerâmico são, entre outras, desplacamento do revestimento, fissuras e trincas, 
eflorescência, manchamento, deterioração do revestimento e corrosão [3]. Entre esses danos, o desplacamento cerâmico é o mais estudado, por reduzir a vida útil do edifício e ser um fator de risco para pedestres e carros que circulam nas proximidades dos edifícios. A definição dos materiais e dos projetos constituem etapas importantes na execução do revestimento externo, a fim de evitar o surgimento dessas manifestações patológicas. No que concerne ao revestimento cerâmico, é fundamental a escolha correta das placas, rejuntes, argamassas e a especificação das juntas, para que sejam compatíveis entre si e desempenhem sua função corretamente. Já as juntas de movimentação nas fachadas devem ser consideradas como um subsistema independente e possuir um projeto específico que analise a questão estrutural e a durabilidade dos materiais utilizados no preenchimento [4].

O desplacamento cerâmico pode ocorrer por diversas causas, atuando em conjunto ou separadamente. Para ajudar na análise, é importante observar a forma do desplacamento, ou seja, em qual camada do revestimento houve o desprendimento. Se a argamassa de fixação da cerâmica permanecer na base e apenas a placa descolar, significa que pode ter havido retração da base, expansão das peças cerâmicas, preparação incorreta do substrato, material de fixação impróprio, erro de execução durante o assentamento e/ou movimentações térmicas. Porém, se a argamassa de fixação se descolar com a cerâmica, o problema não estará relacionado com a cerâmica em si, e sim com a aderência da argamassa à base [5]. Os locais de maior incidência dessa anomalia são panos fechados, trechos curvos, fachada voltada para o lado oeste e partes com cerâmica de cor escura, segundo estudo realizado na cidade de Recife [6]. Outros fatores que influenciam significativamente no aparecimento desse problema são as ausências de juntas de dilatação que geram elevados esforços no revestimento [7] e a falha de preenchimento do tardoz [6]. Também os fatores climáticos influenciam em quase todas as manifestações patológicas identificadas nas fachadas e o desplacamento cerâmico é o que está mais associado a esses fatores [8]. Os panos de fachada com maior incidência do sol e da chuva podem sofrer variações bruscas de temperatura que se caracterizam pelo choque térmico [9]. O choque térmico gera tensões que atuam na argamassa colante de fachadas de edificações por meio da ação da fadiga termomecânica e no revestimento externo com cerâmica. O sistema falha mais rápido com placas de cor escura do que com as de cor clara. Isso ocorre porque o coeficiente de absorção térmica da escura é maior, o que ocasiona maior concentração de calor na estrutura [1]. Outro ponto relacionado à cor da cerâmica é que ela influencia na fadiga, pois, nos sistemas com cerâmica escura, as tensões de fadiga são maiores em virtude de a dilatação térmica nessa cerâmica ser maior.

Após essas análises, constata-se que, para identificar as manifestações patológicas que incidem nas fachadas, é necessário realizar inspeções que quantifiquem e qualifiquem tais danos. A metodologia para que se realizem essas inspeções não é normatizada, mas existem apenas algumas diretrizes nacionais [10], que orientam os profissionais na execução das vistorias. As inspeções de fachadas devem ser periódicas, programadas e realizadas por profissionais habilitados. A cada inspeção deve ser gerado um relatório que será um guia para a próxima inspeção e para a execução de manutenções. Em fachadas com revestimento cerâmico, as inspeções normalmente são visuais e/ou por meio do teste de percussão, e o ideal é que antes seja realizada a lavagem da fachada com jato d'água pressurizada, para facilitar a visualização das manifestações patológicas [11]. Apesar da ausência de normatizações, muitas pesquisas já foram realizadas nesse contexto, no Brasil e no mundo. Em Portugal, inúmeras pesquisas tiveram o objetivo de propor metodologias de inspeção tanto de edificações quanto de fachadas e ainda avaliar a sua degradação ao longo do tempo. Em Portugal, foram analisadas e quantificadas as manifestações patológicas e definidos os níveis de degradação por região de fachada, tais como no entorno das aberturas, no topo, nas paredes contínuas e em outras [12]. Em outro estudo [13], foi proposta para revestimento cerâmico uma ferramenta de inspeção, na qual codificaram os tipos de anomalias, suas causas, métodos de diagnósticos e técnicas de reparo, para analisar, por meio de matrizes de correlação, como esses fatores estão interligados. No Brasil, também são desenvolvidas pesquisas que buscam entender os mecanismos de degradação que ocorrem nas fachadas, bem como os respectivos danos. E, para a avaliação global das fachadas, a definição da melhor forma de inspeção ainda está em desenvolvimento, mas já apresentou avanços com pesquisas que contribuíram para a evolução do conhecimento [8, 14-17].

No Espírito Santo, mais especificamente em Vila Velha, cidade vizinha de Vitória, uma das primeiras pesquisas no ramo de inspeção de fachadas buscou identificar as manifestações patológicas e avaliar o nível de degradação das fachadas de edifícios à beira-mar da cidade, por meio do índice de incidência de manifestações patológicas [3]. Com base no exposto, foi detectada uma lacuna na área de conhecimento das manifestações patológicas, mais incidentes nas fachadas de Vitória-ES, bem como de um levantamento quantitativo e qualitativo por meio do uso do método de níveis de deterioração. Isso porque muitas fachadas da cidade já apresentavam manifestações patológicas em edificações tanto novas quanto antigas, pois podem ter sido originadas desde a concepção do projeto até a forma de manutenção utilizada no local. A cidade de Vitória-ES possui edifícios com três tipos predominantes de revestimento externo das fachadas (cerâmico, pintura e rochas ornamentais), os quais podem ser utilizados em conjunto ou não. Outro tipo de revestimento externo que está se tornando notável na cidade, principalmente nos edifícios comerciais, é o ACM (alumínio composto). Neste artigo, porém, apresenta-se uma metodologia para inspeção de fachadas com revestimento cerâmico. Propõe-se definir um método para realizar um levantamento quantitativo das manifestações patológicas e uma análise qualitativa da degradação nas fachadas, além de realizar ensaios que 
forneçam subsídios para o diagnóstico dos problemas.

\section{MÉTODOS}

Foram realizadas vistorias em fachadas com revestimento cerâmico de três edifícios da cidade de Vitória-ES, com intuito de sistematizar o registro e a análise das manifestações patológicas. E, com objetivo de complementar o diagnóstico dos danos, foram feitos ensaios in loco e em laboratório. A metodologia desta pesquisa foi dividida em três etapas: 1) definição da metodologia de inspeção de fachadas; 2) levantamento de dados; e 3) tratamento dos dados e análise dos resultados. A $1^{a}$ etapa consistiu na definição de três variáveis de controle para a seleção dos edifícios: a idade entre 20 e 40 anos para obter métodos construtivos similares; a localização na cidade de Vitória-ES, com distância máxima, em linha reta, de 1500 m entre eles; tipo de revestimento: maior área de fachada com revestimento cerâmico. Além das variáveis de controle, foram utilizados métodos pré-estruturados $[8,12,13,17]$ para a definição da metodologia desta pesquisa. $\mathrm{Na} 2^{\mathrm{a}}$ etapa, foram selecionados os edifícios com base nos seguintes critérios: apresentar manifestações patológicas aparentes, viabilizar o acesso ao edifício e permitir a divulgação dos dados e a realização de ensaios não destrutivos. Com isso, foram escolhidos três edifícios com área total de revestimento cerâmico de $4958 \mathrm{~m}^{2}$. Os
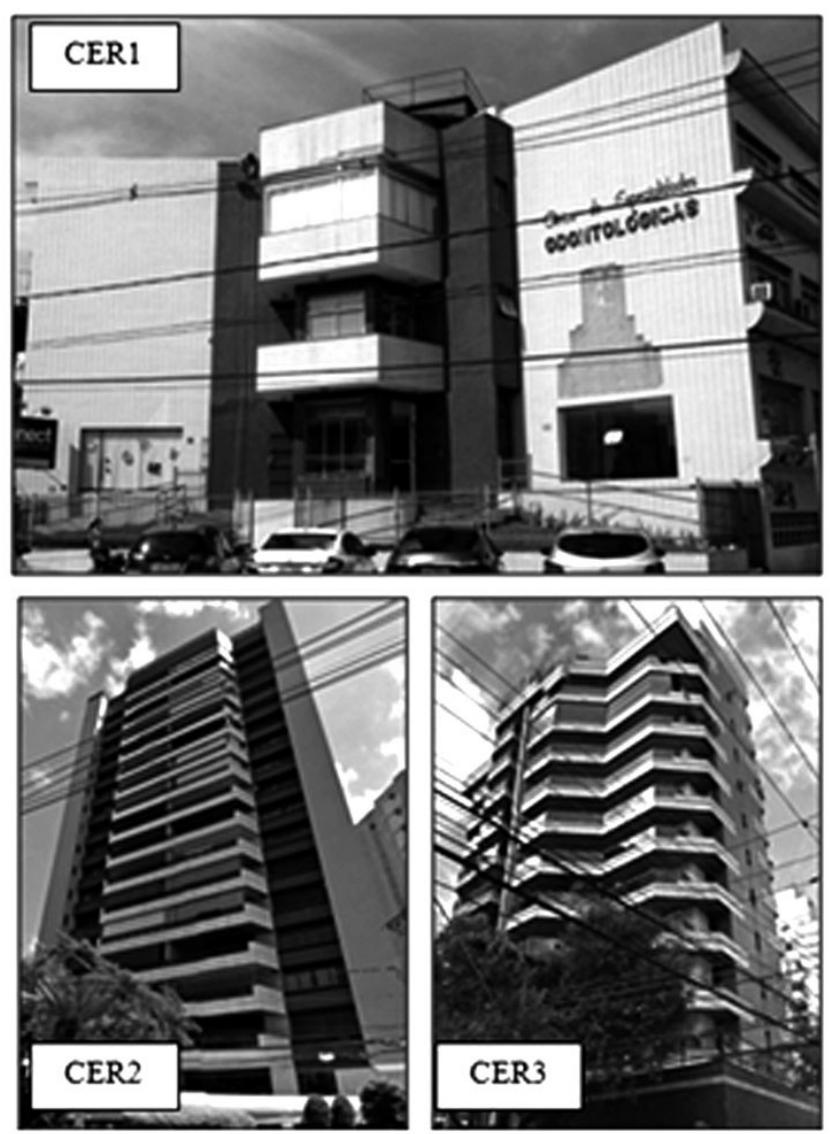

Figura 1: Fotografias dos edifícios vistoriados.

[Figure 1: Photos of inspected buildings.] edifícios foram nomeados CER1, CER2 e CER3 em razão de as fachadas possuírem predominantemente cerâmica no revestimento externo e no intuito de preservar a identidade dos prédios (Fig. 1).

Após a fase de seleção dos edifícios, iniciou-se a vistoria inicial para realizar o desenho de todos os croquis da edificação: da planta baixa e das fachadas. No croqui da planta baixa do edifício, foram identificadas as orientações cardeais de cada fachada. Por meio dos croquis, foram calculadas as áreas de fachada por orientação cardeal e a área total de fachadas do edifício. Para cada área bruta, calcularam-se a área líquida e a área de realização do teste de percussão: a área bruta correspondeu à área integral da fachada; a líquida equivaleu à área vistoriada, ou seja, a área bruta descontando-se as áreas das aberturas e de tipos diferentes de revestimento (exemplo: pedra). Posteriormente foram realizadas entrevistas com os responsáveis para obter o máximo de informações possíveis, desde as documentações até os dados sobre as manutenções já realizadas. Em seguida, foram realizadas as inspeções das fachadas para o levantamento e análise das manifestações patológicas existentes, registradas por meio de fotos, croquis e fichas de vistoria. A inspeção foi realizada por orientação cardeal de fachada e por região (nível do solo, paredes contínuas, aberturas, topo, sacadas, cantos e extremidades, juntas, transição entre pavimentos), conforme Fig. 2. O registro das manifestações patológicas foi feito mediante códigos, conforme Tabela I. Para cada código registrado, anotou-se a respectiva área de ocorrência (em metros quadrados) e o nível de degradação de 1 a 4 (1 para a melhor situação e 4 para a pior), como se nota na Tabela II.

Finalizada a parte de inspeção visual das fachadas, iniciou-se a parte final do levantamento de dados, que

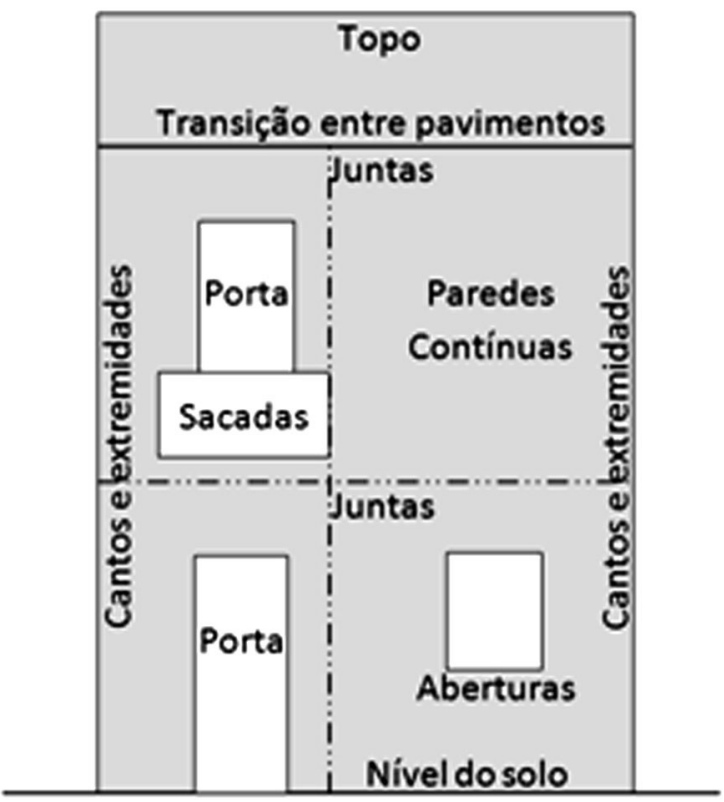

Figura 2: Representação esquemática das regiões da fachada (adaptado de $[8,11])$.

[Figure 2: Schematic of the regions of facade (adapted from [8, 11]).] 
Tabela I - Classificação das anomalias no revestimento cerâmico (adaptado de [13]).

[Table I - Classification of anomalies in ceramic coating (adapted from [13]).]

\begin{tabular}{|c|c|}
\hline D.1_a & $\begin{array}{l}\text { Descolamento na camada exterior (entre a } \\
\text { cerâmica e a argamassa de assentamento) }\end{array}$ \\
\hline D.s & $\begin{array}{l}\text { Descolamento do sistema de revestimento } \\
\text { cerâmico }\end{array}$ \\
\hline D.s1 & $\begin{array}{l}\text { Na interface material de assentamento/camada } \\
\text { de regularização da base (reboco) }\end{array}$ \\
\hline D.s2 & $\begin{array}{l}\text { No meio da camada de regularização da base (no } \\
\text { seio do reboco) }\end{array}$ \\
\hline D.s3 & Na própria base \\
\hline D.p & $\begin{array}{l}\text { Revestimento que apresenta som cavo pelo teste } \\
\text { de percussão }\end{array}$ \\
\hline F.1_a & Fissuração na camada exterior \\
\hline F.s & Fissuração do sistema de revestimento cerâmico \\
\hline F.s1 & Da base propagada para o revestimento \\
\hline F.s2 & Nas juntas de dilatação da base \\
\hline F.s3 & Em zonas de concentração de tensões na base \\
\hline Dt.l & Deterioração das placas cerâmicas \\
\hline Dt.11 & Esmagamento ou lascamento das bordas \\
\hline Dt.12 & Desgaste ou risco \\
\hline Dt.13 & Eflorescência/criptoeflorescência \\
\hline Dt.14 & Pequenas crateras sobre a superfície \\
\hline Dt.j & Deterioração das juntas (rejuntes) \\
\hline Dt.j1 & Eflorescência/criptoeflorescência \\
\hline Dt.j2 & Alteração de cor \\
\hline Dt.j3 & $\begin{array}{l}\text { Fissura/perda de massa no seio do material de } \\
\text { preenchimento das juntas (rejuntes) }\end{array}$ \\
\hline Dt.j4 & Descolamento \\
\hline Dt.j5 & Organismos vegetais \\
\hline Dt.j6 & Consistência pulverulenta \\
\hline E.s & Manifestações patológicas estéticas \\
\hline E.s1 & $\begin{array}{l}\text { Deficiência de planeza ou existência de } \\
\text { irregularidades na superfície do revestimento }\end{array}$ \\
\hline E.s2 & $\begin{array}{l}\text { Manchas, alteração de cor ou alteração de brilho } \\
\text { das placas cerâmicas }\end{array}$ \\
\hline E.s3 & $\begin{array}{l}\text { Fissuração ou gretamento do esmalte das placas } \\
\text { cerâmicas }\end{array}$ \\
\hline \multirow[t]{2}{*}{ M } & Manchas e sujeiras \\
\hline & Manifestações patológicas nas fachadas \\
\hline DC & Desagregação do concreto \\
\hline $\mathrm{C}$ & Corrosão \\
\hline
\end{tabular}

consistiu na realização dos ensaios não destrutivos. Procedeu-se aos ensaios de teste de percussão nas fachadas, absorção de água e expansão por umidade das placas cerâmicas. O teste de percussão foi realizado nas fachadas mais representativas (em termos de extensão, nível crítico e cor das cerâmicas). Durante o teste de percussão, foi autorizada, por parte dos condomínios, a retirada de amostras do revestimento que estavam com risco de queda. Com essas amostras foram realizados os ensaios de absorção de água e expansão por umidade das placas cerâmicas. Cada ensaio foi descrito no formato de ficha técnica [13] para facilitar a execução e garantir a realização conforme a metodologia discriminada. Para detectar os locais com revestimentos soltos, ou seja, que apresentavam som cavo, foi realizado o teste de percussão conforme preconiza a ABNT NBR 13749:2013. A área que apresentou som cavo por esse teste foi identificada nas fichas de vistoria de manifestação patológica, assim como as demais anomalias, por orientação de fachada e por região, utilizando o código D.p - revestimento que apresenta som cavo pelo teste de percussão. Foi registrada também a área total de realização do teste. Entretanto, como a área vistoriada não foi a mesma da inspeção visual, os resultados foram apresentados separadamente. Para os ensaios de absorção de água e expansão por umidade das placas cerâmicas, foi necessário utilizar as que estavam nas fachadas, por não existirem placas iguais no mercado ou sobressalentes nos edifícios. Devido a isso, foi necessário realizar a limpeza do tardoz das cerâmicas, para retirar a argamassa que estava aderida à placa (Fig. 3). Esses ensaios foram executados conforme orientações da ABNT NBR 13818:1997 - Anexos B e J [18], para absorção de água e expansão por umidade, respectivamente. Na Fig. 4 mostram-se as placas cerâmicas dos edifícios utilizadas nos ensaios de absorção de água e expansão por umidade. As cerâmicas dos edifícios CER1 e CER3 foram similares na aparência: tamanho $10 \mathrm{~cm} \times 10 \mathrm{~cm}$; tardoz poroso e com mesmo desenho; mesmo fabricante; cor escura. Entretanto, a cerâmica de CER3 possuiu coloração mais clara no tardoz e acabamento brilhante texturizado. Já as cerâmicas de CER2 foram diferentes das dos demais edifícios: tamanho $4 \mathrm{~cm} \mathrm{x} 4 \mathrm{~cm}$, tardoz liso; acabamento com superfície lisa e brilhante.

$\mathrm{Na} 3^{\text {a }}$ etapa, foi realizado o tratamento dos dados para avaliação e diagnósticos dos danos identificados. Para isso foram definidos os seguintes parâmetros: índice de manifestação patológica - IMP (Equação A) [17], porcentagem de ocorrência de cada manifestação patológica - \%MP (Equação B) e a porcentagem de ocorrência de cada nível de degradação - \% $\mathrm{ND}_{\mathrm{n}}$ (Equação C) [12], além do nível de degradação médio - ND (Equação D), conforme:

$\mathrm{IMP}=\frac{\sum \text { Área degradada de cada manifestação patológica }}{\text { Área líquida vistoriada }}(\mathrm{A})$

$\% \mathrm{MP}=\frac{\sum \text { Área de ocorrência da MP na região }}{\sum \text { Área de ocorrência de todas as MP na região }} \times 100$ 
Tabela II - Nível de degradação para os edifícios com revestimento cerâmico (adaptado de [12]).

[Table II - Degradation level for buildings with ceramic coating (adapted from [12]).]

\begin{tabular}{ccc}
\hline $\begin{array}{c}\text { Nível 1 } \\
\text { Melhor condição }\end{array}$ & Manchas na superfície & Acesso visual \\
\hline $\begin{array}{c}\text { Nível 2 } \\
\text { Degradação suave }\end{array}$ & $\begin{array}{c}\text { Fissuração (visível somente com binóculo); gretamento; dano suave } \\
\text { nos rejunte e nas placas cerâmicas; grafite; presença localizada de } \\
\text { bolor; possível infiltração de água ou sinais suaves de eflorescência; } \\
\text { organismos vegetais; mancha por umidade }\end{array}$ & $\begin{array}{c}\text { Limpeza da } \\
\text { superfície } \\
\text { (escovação e } \\
\text { lavagem) }\end{array}$ \\
\hline $\begin{array}{c}\text { Nível 3 } \\
\text { Degradação moderada }\end{array}$ & $\begin{array}{c}\text { Fissuração localizada (visível a olho nu); cantos ou bordas danificadas; } \\
\text { dano intenso nos rejuntes e nas placas cerâmicas; eflorescências }\end{array}$ & Reparo e proteção \\
\hline $\begin{array}{c}\text { Nível 4 } \\
\text { Degradação intensa }\end{array}$ & $\begin{array}{c}\text { Fissuração intensa; descolamento ou desagregação da superfície; } \\
\text { elementos de aço quebrados ou corroídos; perda de aderência entre } \\
\text { camadas; destacamento da parede }\end{array}$ & $\begin{array}{c}\text { Substituição parcial } \\
\text { ou completa }\end{array}$ \\
\hline
\end{tabular}

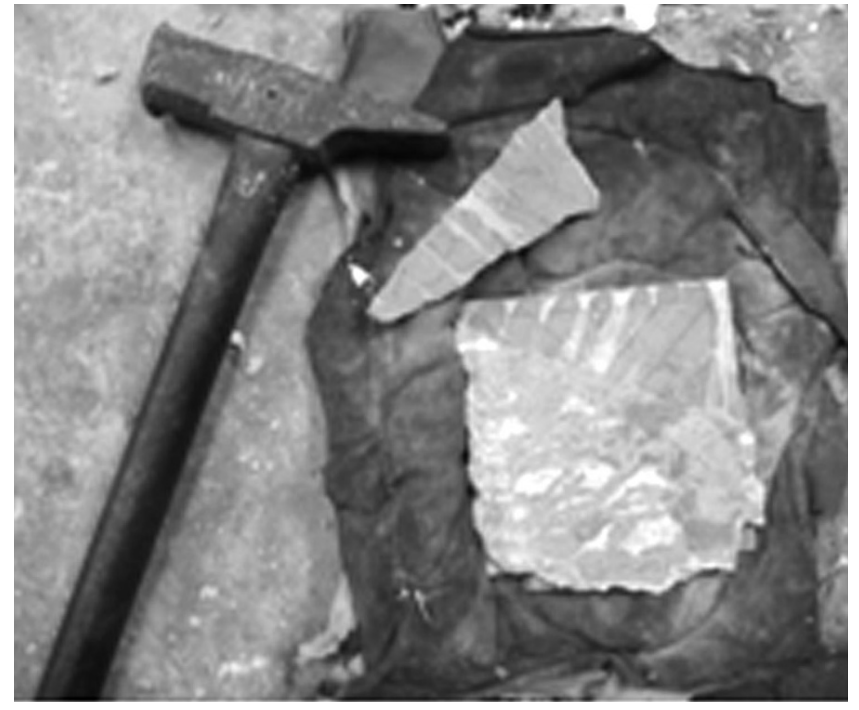

Figura 3: Fotografia mostrando a retirada da argamassa aderida à cerâmica.

[Figure 3: Photo showing the mortar removal adhered to the ceramic.]

$$
\begin{aligned}
& \% \mathrm{ND}_{\mathrm{n}}=\frac{\mathrm{A}_{\mathrm{n}}}{\mathrm{A}_{1}+\mathrm{A}_{2}+\mathrm{A}_{3}+\mathrm{A}_{4}} \times 100 \\
& \mathrm{ND}=\frac{\left(\mathrm{A}_{1} \times 1\right)+\left(\mathrm{A}_{2} \times 2\right)+\left(\mathrm{A}_{3} \times 3\right)+\left(\mathrm{A}_{4} \times 4\right)}{\mathrm{A}_{1}+\mathrm{A}_{2}+\mathrm{A}_{3}+\mathrm{A}_{4}} \times 100
\end{aligned}
$$

onde, \%NDn é a porcentagem de ocorrência do nível n (varia de 1 a 4), $A_{n}$ é a área degradada com nível de degradação n (varia de 1 a 4), $A_{1}+A_{2}+A_{3}+A_{4}$ é o somatório das áreas degradadas na região de fachada, ND é o nível de degradação médio da manifestação patológica obtido por média ponderada e $(\mathrm{A} 1 \times 1)+(\mathrm{A} 2 \times 2)+(\mathrm{A} 3 \times 3)+(\mathrm{A} 4 \times 4)$ é o somatório das áreas degradadas de cada nível de degradação vezes o respectivo nível de degradação. A análise das prováveis causas de cada manifestação patológica foi definida com base em uma matriz de correlação entre os danos e as respectivas causas [13]. As causas foram
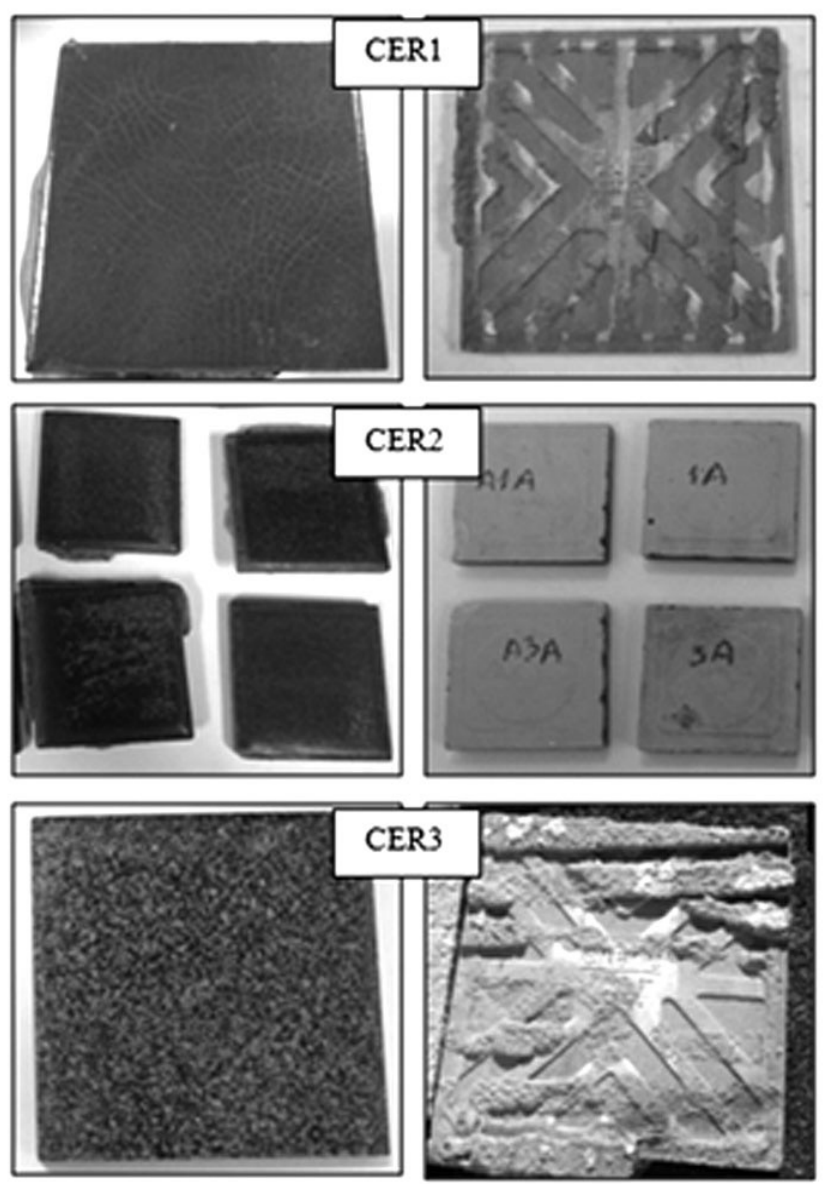

Figura 4: Fotografias das cerâmicas utilizadas nos ensaios de absorção de água e expansão por umidade.

[Figure 4: Photos of ceramics used in the water absorption test and expansion by moisture test.]

classificadas em função de sua origem: falha de projeto; erro de execução; comportamento em uso; ações ambientais e falhas de manutenção (Tabela III).

\section{RESULTADOS E DISCUSSÃO}

Com base nas entrevistas e análises iniciais, foram 
Tabela III - Classificação das prováveis causas no sistema de revestimento cerâmico (adaptado de $[8,13]$ ). [Table III - Classification of probable causes in the ceramic coating system (adapted from [8, 13]).].

\section{C-A Falhas de projeto}

C-A1 escolha de material incompatível, omissa ou não adequada à utilização

C-A2 revestimento externo não conforme com as características da base (estrutura/ alvenaria)

C-A3 prescrição de colagem simples em vez de dupla

C-A4 inexistência de juntas de assentamento de movimentação ou estruturais
C-A5 especificação incorreta de peitoris C-A6 ausência de pingadeiras

C-A7 ausência de vergas e contravergas nas aberturas C-A8 ausência de impermeabilização no nível do solo

\section{C-B Erros de execução}

C-B1 utilização de materiais não prescritos e/ou incompatíveis entre si

C-B2 aplicação em condições ambientais extremas

C-B3 desrespeito pelos tempos de espera entre as várias fases de execução

C-B4 aplicação em bases sujas, pulverulentos ou não regulares

C-B5 desrespeito pelo tempo em aberto da argamassa colante

C-B6 espessura inadequada do material de assentamento

C-B7 contato incompleto placa cerâmica/material de assentamento

C-B8 colagem simples em vez de dupla
C-B9 utilização de material de assentamento ou de preenchimento dos rejuntes de retração elevada

C-B10 não execução de juntas

C-B11 revestimento externo não conforme com as características da base (estrutura/alvenaria)

C-B12 execução incorreta de peitoris

C-B13 ausência e/ou execução incorreta de pingadeiras

C-B14 ausência e/ou execução incorreta de vergas e contravergas nas aberturas

C-B15 ausência e/ou execução de impermeabilização no nível do solo

\section{C-C Comportamento em uso}

C-C1 choques contra o RCA

C-C2 vandalismo/grafite
C-C3 concentração de tensões na base

C-C4 acomodação estrutural
C-D1 vento
$\mathrm{C}-\mathrm{D} 2$ radiação solar
C-D3 choque térmico
C-D4 lixiviação dos materiais do RCA que contêm cimento
C-D5 focos de umidade

C-D Ações ambientais
C-D6 ação biológica
C-D7 poluição atmosférica
C-D8 envelhecimento natural
C-D9 incidência da chuva

C-E Falha de manutenção

C-E1 falta de limpeza do sistema de revestimento cerâmico ou de zonas adjacentes
C-E2 ausência/erro de troca de componentes do sistema de revestimento cerâmico obtidas as principais informações sobre os edifícios (Tabela IV). Algumas especificações sobre os prédios são importantes para melhor entendimento dos resultados. $\mathrm{O}$ edifício CER1 de uso comercial possuiu revestimento cerâmico com placas $20 \mathrm{~cm} \mathrm{x} 10 \mathrm{~cm}$ e $10 \mathrm{~cm}$ x $10 \mathrm{~cm}$ nas cores branca e vinho e não houve nenhum tipo de junta de movimentação. Inicialmente possuía revestimento externo em pintura, o qual foi substituído por cerâmica 18 anos após a inauguração. Com relação à manutenção, foi realizada apenas a corretiva eventualmente para retirada de cerâmicas com risco iminente de queda. A influência do sol sobre as fachadas foi analisada com base na carta solar da cidade de Vitória, na qual se constatou que o Sol nasce entre as fachadas sudeste e lés-nordeste, variando ao longo do ano, e se põe sempre à fachada dos fundos. E, com relação ao somatório da radiação solar, a fachada norte (lateral direita) possuiu maior incidência de radiação.

$\mathrm{O}$ edifício CER2 é residencial, com revestimento externo com pastilhas $4 \mathrm{~cm} \times 4 \mathrm{~cm}$ e $2 \mathrm{~cm} \times 2 \mathrm{~cm}$, nas cores branca, bege e vinho, também sem nenhuma junta de movimentação. Para análise da incidência solar, observou-se que o sol nasce ao longo do ano entre as fachadas su-sudeste e lés-nordeste e se põe predominantemente na fachada oés-sudoeste. Já com relação à incidência da radiação solar, observou-se que a fachada nor-nordeste foi a de maior intensidade e a susudeste a de menor intensidade. Nesse edifício, foi realizado um laudo de inspeção predial em 2013, o qual classificou as fachadas como críticas em relação ao grau de risco [10] e solicitou recuperação imediata devido à perda de desempenho do sistema. Ainda destacou a necessidade de realização do teste de percussão na fachada e o ensaio de arrancamento, para avaliar a presença de revestimentos que apresentavam som cavo e a resistência à tração, respectivamente [19]. Entretanto, apenas o teste de percussão foi realizado. Quanto à recuperação imediata solicitada, somente em parte da fachada o revestimento cerâmico foi retirado, para reduzir $\mathrm{o}$ risco de danos à integridade das pessoas e materiais. $\mathrm{O}$ terceiro edifício, CER3, possuiu fachadas revestidas por placas $10 \mathrm{~cm}$ x $10 \mathrm{~cm}$, nas cores cinza, azul e branca. Não foi observado nenhum tipo de junta de movimentação. Quanto à manutenção nas fachadas, só foi realizada a corretiva, que, assim como em CER1, retirou as cerâmicas 
Tabela IV - Resumo das informações dos edifícios.

[Table IV - Brief data of the buildings.]

\begin{tabular}{ccccccc}
\hline \multirow{2}{*}{ Edifício } & \multirow{2}{*}{ Idade (ano) } & Frente & Lateral direita & Lateral esquerda & Fundo & \multirow{2}{*}{ N $^{\mathrm{o}}$ andar } \\
\hline CER1 & 38 & Lés-nordeste & Norte & Sudeste & - & 4 \\
CER2 & 30 & Lés-nordeste & Nor-nordeste & Su-sudeste & Oés-sudoeste & 16 \\
CER3 & 22 & Noroeste & Nordeste & Sudoeste & Sudeste & 12 \\
\hline
\end{tabular}

que apresentavam risco iminente de queda. Foi realizado um laudo simplificado, em 2014, de análise das fachadas, o qual aconselhou a substituição do revestimento por pintura. Após a análise da carta solar de Vitória, constatou-se que o Sol nasce entre as fachadas nordeste e sudeste ao longo do ano e se põe entre as fachadas noroeste e sudoeste. E, com relação à incidência da radiação solar, observou-se que as fachadas nordeste e noroeste foram as de maior intensidade e as sudeste e sudoeste as de menor intensidade.

Após as vistorias, foram detectados 17 tipos de manifestações patológicas. Com base na Fig. 5, observamse as manifestações patológicas de maior ocorrência nos três edifícios. Concluiu-se que as manchas e sujeiras (M) foram danos recorrentes aos três edifícios e com alta representatividade. Ocorreram principalmente pela deposição de partículas sólidas na superfície do revestimento, oriundas da poluição atmosférica. Esse tipo de anomalia é muito comum nos edifícios de Vitória devido à proximidade com grandes indústrias de siderurgia e mineração. O nível de degradação médio foi igual a 2, pois se tratou de um dano suave. O desplacamento cerâmico (D.s1) visível teve maior ocorrência apenas em CER1. Entretanto, todos os edifícios apresentaram áreas com revestimento solto pelo teste de percussão. A alteração de cor/brilho nas cerâmicas (E.s2) foi observada com maior incidência em CER2, o

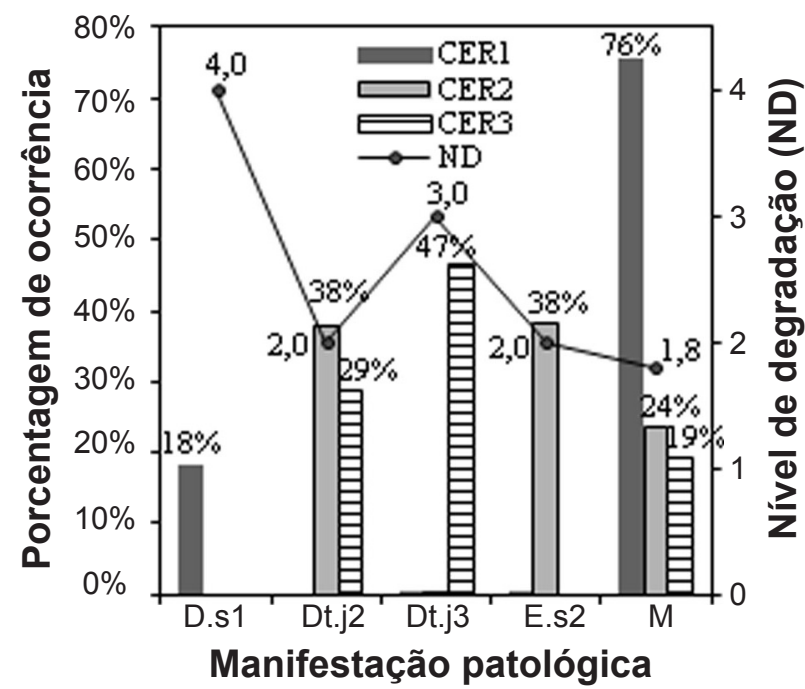

Figura 5: Gráfico das principais manifestações patológicas nos três edifícios.

[Figure 5: Graph of the main pathological manifestations in the three buildings.] que foi associada à característica da cerâmica em conjunto com o envelhecimento natural e às ações externas, como o sol. As fissuras nos rejuntes (Dt.j3) de CER3 foram relacionadas ao tipo de material utilizado, pois as fissuras estavam perpendiculares às cerâmicas. Já a alteração de cor dos rejuntes (Dt.j2) teve maior ocorrência nos edifícios CER2 e CER3. Além desses danos de maior ocorrência nos edifícios, foram observadas outras manifestações patológicas que ocorreram de forma pontual. As fissuras na camada exterior (F.s1 e F.s2) foram observadas apenas no edifício CER2 e foram relacionadas com a movimentação da base do revestimento. Com relação à deterioração das placas cerâmicas, no edifício CER3 observou-se a quebra das bordas (Dt.11) em duas placas, o que foi associada a algum choque mecânico sobre elas durante a execução, uso ou manutenção. Já em CER2, foi detectada uma pastilha com uma cratera na superfície (Dt.14) também associada a algum choque mecânico.

As anomalias de deterioração dos rejuntes com menor ocorrência foram a eflorescência (Dt.j1) e organismos vegetais (Dt.j5). A eflorescência ocasionada pelo transporte dos compósitos do cimento foi detectada em locais de CER3, nos quais havia presença de umidade na parte interna do edifício (banheiro, cobertura e jardineira), que propiciou esse dano. Já os organismos vegetais foram identificados na região do nível do solo de CER1, pela concentração de umidade nessa região, e em CER3 próximo às varandas, por transposição eólica associada à umidade. As manifestações patológicas de ordem estética, como a deficiência de planeza (E.s1) e o gretamento das placas (E.s3), foram pouco observadas durante a inspeção visual. A deficiência de planeza ocorreu por erro de execução do assentamento das cerâmicas e o gretamento foi associado à característica das cerâmicas. Em CER2 também foram observados a corrosão das armaduras (C) e o desplacamento do concreto (DC), pontualmente em uma fachada.

Tabela V - Nível de degradação e IMP.

[Table V-Degradation level and IMP.]

\begin{tabular}{cccc}
\hline Edifício & $\begin{array}{c}\text { Idade } \\
\text { (ano) }\end{array}$ & $\begin{array}{c}\text { Nível de } \\
\text { degradação } \\
\text { médio }\end{array}$ & IMP \\
\hline CER1 & $38(20)$ & 2,33 & 0,24 \\
CER.2 & 30 & 2,05 & 0,78 \\
CER3 & 22 & 2,48 & 0,10 \\
\hline
\end{tabular}




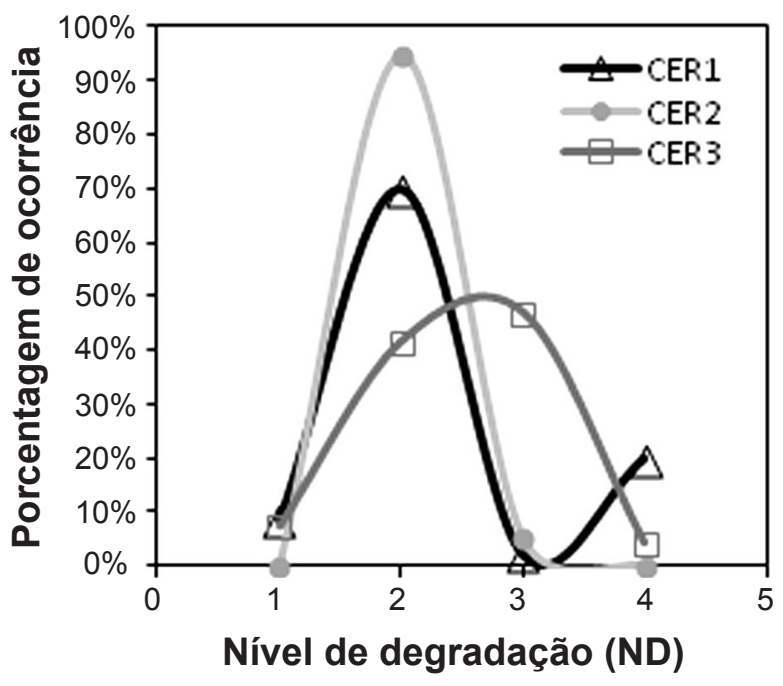

Figura 6: Curvas das porcentagens de ocorrência de cada nível de degradação nos edifícios.

[Figure 6: Curves of occurrence percentages of each degradation level in the buildings.]

Os índices de manifestação patológica (IMP) e níveis de degradação (ND) dos edifícios estão na Tabela V. O edifício CER1 possuía 38 anos de idade, mas, para efeitos comparativos, foi considerada a idade do revestimento externo cerâmico de 20 anos, apesar da influência do substrato sobre o revestimento externo. Com isso, ao observar CER1 e CER3, notou-se que o mais antigo apresentou maior ND e menor IMP, o que mostra que os parâmetros devem ser avaliados em conjunto, pois, apesar da menor incidência, os danos possuem maior gravidade. Já CER2 apresentou alto IMP, mas com ND baixo, relacionado à extensa área com anomalias associadas à estética do revestimento. Ao analisar as curvas com a porcentagem de ocorrência de cada índice de degradação nos três edifícios (Fig. 6), observou-se que o nível de degradação 2 foi associado à grande parte das manifestações patológicas dos três edifícios. Os edifícios CER1 e CER2 apresentaram comportamento semelhante das curvas, com a diferença da menor ocorrência do nível 4 em CER2. Já o nível 3 foi o de maior ocorrência no edifício CER3.

\section{Análise dos desplacamentos}

Foram observados três tipos de desplacamento cerâmico nos edifícios: D.1_a - descolamento na camada exterior (entre a cerâmica e a argamassa de assentamento); D.s1 - descolamento do sistema de revestimento cerâmico na interface material de assentamento/camada de regularização da base (reboco); e D.p - revestimento que apresenta som cavo pelo teste de percussão. Este último foi observado nos três edifícios. No edifício CER1, foram detectados desplacamentos entre a cerâmica e a argamassa de assentamento (D.1_a) e na interface material de assentamento/reboco (D.s1). Entre os dois, o de maior incidência foi D.s1, correspondendo a $92 \%$ do total de

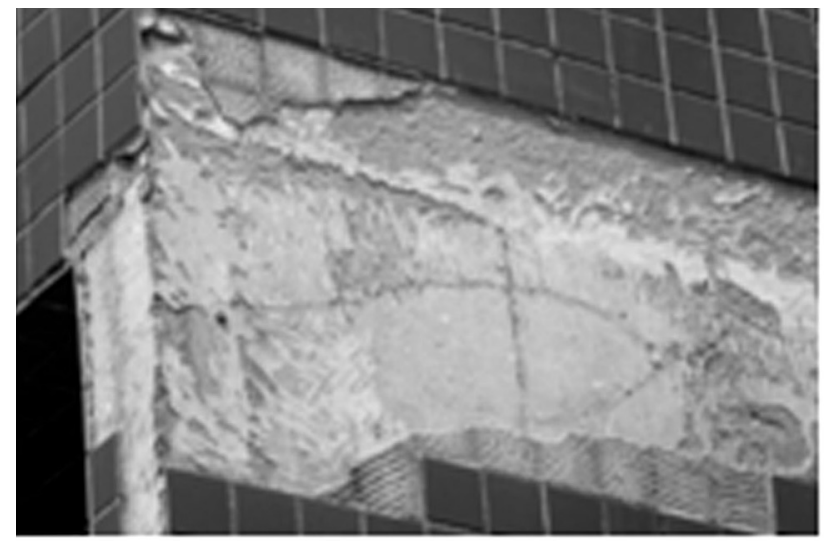

Figura 7: Fotografia mostrando resquícios da pintura. [Figure 7: Phto showing remnants of paint.]
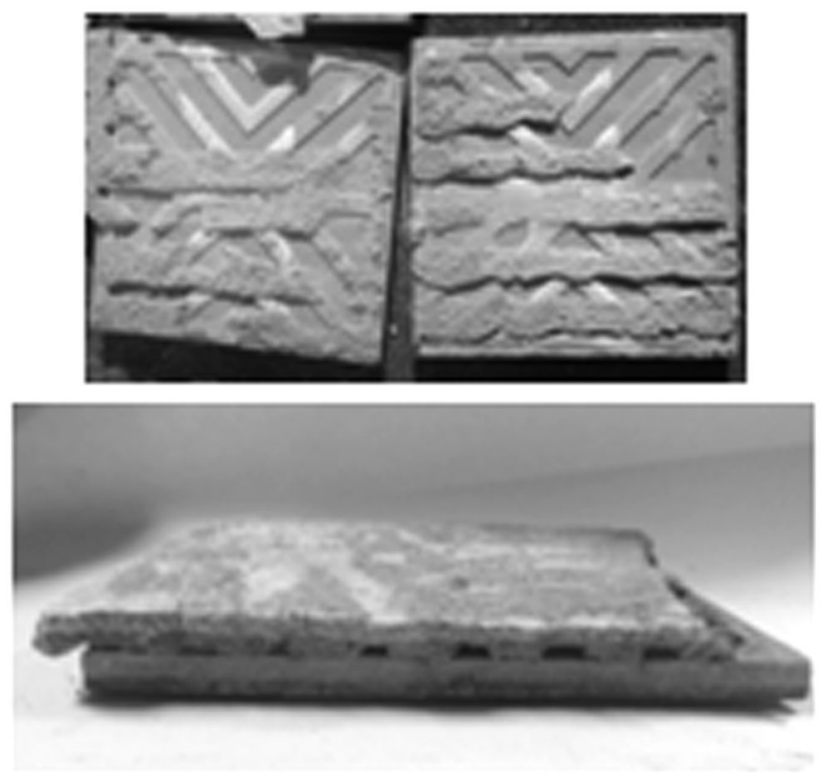

Figura 8: Fotografias de cerâmica com cordões de argamassa visíveis.

[Figure 8: Photos of ceramic with visible mortar cords.]

revestimento descolado. O tipo D.1_a equivaleu apenas a $8 \%$ do total, ou seja, houve falha na aderência entre a argamassa de assentamento e o reboco. Essa falha pode ser justificada pela presença de resquícios da pintura sobre o reboco, proveniente do revestimento externo antigo do edifício que não foi retirado corretamente para a realização do assentamento cerâmico (Fig. 7). Durante a preparação das cerâmicas para os ensaios de laboratório, observou-se que a argamassa de assentamento de CER1 estava fortemente aderida, devido à dificuldade de sua retirada. Entretanto, algumas placas apresentavam cordões de argamassa visíveis, indicando falha no preenchimento do tardoz (Fig. 8). O incorreto preenchimento do tardoz ocasionou redução na aderência nesses locais, o que justificou o desplacamento do tipo D.1_a na argamassa de assentamento com a cerâmica.

No edifício CER2, apesar da grande ocorrência de revestimento que apresentava som cavo pelo teste de 


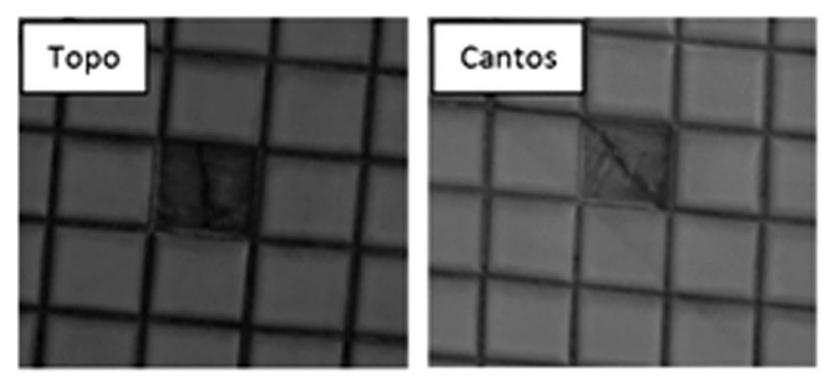

Figura 9: Fotografias mostrando fissuras na argamassa nos locais de desprendimento cerâmico de CER2.

[Figure 9: Photos showing cracking in mortar in the local of ceramic detachment in CER2.]

percussão (D.p), o desplacamento do tipo D.1_a ocorreu pontualmente em alguns locais das fachadas. Mesmo com a baixa incidência, o desplacamento entre a cerâmica e a argamassa de assentamento ocorre em locais com alta circulação de pessoas e carros. É importante observar que as pastilhas desprendem individualmente devido à sua forma de assentamento, não sendo identificadas áreas maiores de desplacamento. Sobre D.1_a, observou-se que, nas fachadas que permitiam maior visibilidade, no local onde houve a queda havia uma pequena fissura na argamassa aderida à fachada, que provavelmente foi a causa do desprendimento (Fig. 9). Essas fissuras foram detectadas nas regiões de topo e extremidades e ocasionadas pelas tensões na base do revestimento. Ao realizar a preparação das cerâmicas para os ensaios de laboratório, observou-se que as pastilhas de CER2 estavam com a argamassa do reboco fortemente aderida ao tardoz. Isso indicou que provavelmente grande parte do revestimento que apresentou som cavo pelo teste de percussão estava com perda de aderência na camada de regularização da base e que esses casos de queda de pastilhas individuais podem estar relacionados ao tempo em aberto da argamassa de assentamento em alguns locais ou à propagação de fissuras.

Assim como CER1, CER3 apresentou desplacamento entre a cerâmica e a argamassa de assentamento (D.1_a) e na interface material de assentamento/reboco (D.s1). Contudo, ao contrário do que ocorreu nas cerâmicas dos demais edifícios, a argamassa colante dessas cerâmicas foi facilmente retirada durante a limpeza do tardoz. Os cordões de argamassa também foram visíveis nessas placas indicando que o tardoz não estava completamente preenchido. Esses fatos indicaram que a falha de aderência em CER3 ocorreu principalmente entre a argamassa de assentamento e a cerâmica, corroborando o desplacamento detectado visualmente, no qual esse tipo correspondeu a $0,4 \%$ da área total vistoriada do edifício. Já o desplacamento entre o reboco e a argamassa de assentamento equivaleu a 0,003\% da área total. Ou seja, com relação a CER1 e CER2, a argamassa de assentamento de CER3 foi mais fraca e mais porosa.

O teste de percussão permitiu analisar a relação entre a cor, a posição das fachadas e as áreas que apresentaram som cavo (D.p). Do total vistoriado de cada edifício de cerâmica com cor escura, CER1 apresentou 20\% de área degradada, enquanto CER2 17\% e CER3 9\%. As cerâmicas de cor clara foram inspecionadas em CER1 e CER2 e corresponderam a $14 \%$ e $4 \%$ de área com som cavo, respectivamente. Ou seja, os três edifícios precisam de intervenções urgentes, mas destaca-se que CER1 é o que está com maior risco de desplacamento cerâmico. Com relação à cor, observou-se que as escuras apresentaram pior desempenho. Esse fato pode ser relacionado com a menor resistência ao choque térmico das cerâmicas de cor escura quando comparadas com as de cor clara [1] e também ao fato de as superfícies escuras possuírem maiores coeficientes de absorção da radiação solar e, com isso, atingirem temperaturas maiores que as de cor clara para as mesmas condições de insolação [20]. As temperaturas mais altas na superfície podem gerar deformações e tensões maiores, o que leva à ruptura precoce. À vista disso, as cerâmicas de cor clara são mais aconselháveis para fachadas [20].

As maiores áreas com revestimento solto foram detectadas na fachada com menor influência da radiação solar (sudeste), no edifício CER1. Já em CER3, foram vistoriadas as fachadas em que incidiu o sol da manhã (nordeste) e o sol da tarde (sudoeste). A fachada nordeste apresentou o dobro de área deteriorada quando comparada com a fachada sudoeste. Tal resultado era esperado, pois a fachada nordeste foi a única com desplacamento cerâmico acentuado visível durante a inspeção e a que recebeu maior intensidade de radiação solar. Como em CER3, os resultados do teste de percussão corroboraram os desplacamentos observados durante as vistorias. Em CER1 e CER2, as fachadas norte e nornordeste foram as de menor ocorrência de desplacamento. Já as fachadas de maior ocorrência de revestimento solto também foram as que apresentaram maior quantidade de desplacamento. Com relação às regiões de fachadas, mostrase na Fig. 10a a porcentagem de ocorrência da manifestação patológica D.p por região de fachada de cada edifício e, na Fig. 10b, mostram-se os danos D.1_a e D.s1. Observou-se que, em CER1, as regiões de paredes contínuas e transição entre pavimentos foram as que possuíram maior porcentagem de ocorrência de áreas que apresentaram som cavo pelo teste de percussão (D.p). Já em CER2, foram as sacadas, das quais todo o revestimento cerâmico estava comprometido em algumas varandas, seguidas pela região de paredes contínuas. No edifício CER2, apesar da baixa incidência nas aberturas, foi observado que nos cantos das básculas havia uma constância de revestimentos com som cavo pelo teste de percussão (D.p), que pode ter sido ocasionada pela provável presença de trincas inclinadas em $45^{\circ}$ nesses locais que fragilizaram a região. Em CER3, esse ensaio foi realizado apenas nas paredes contínuas, transição entre pavimentos e aberturas, o que justificou a alta ocorrência nas duas primeiras regiões.

Com relação aos desplacamentos de cerâmica observado durante a inspeção visual (D.1_a e D.s2, Fig. 10b), verificou-se que nos edifícios CER 1 e CER3 as regiões de paredes contínuas, aberturas e transição entre pavimentos foram as de maior ocorrência desses danos. Em CER3, os 


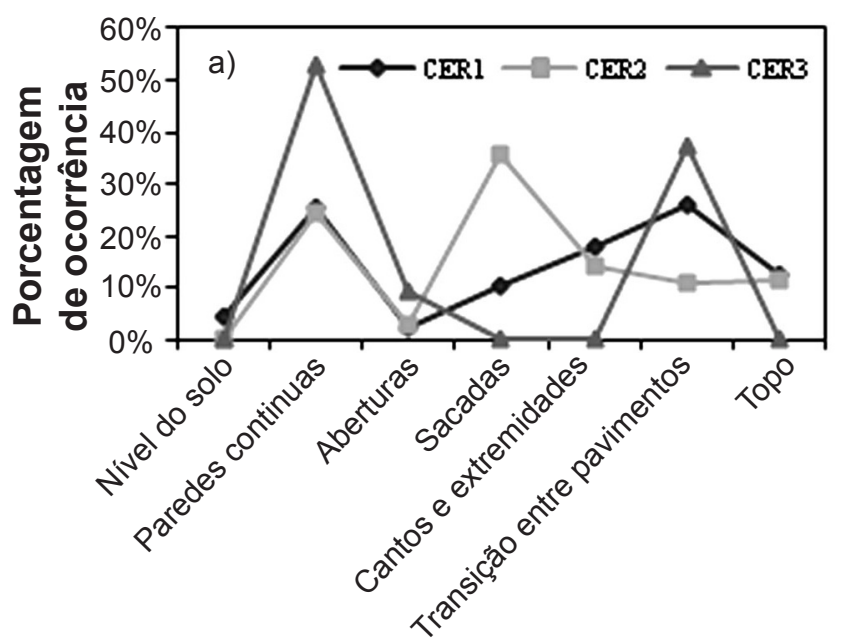

Região da Fachada

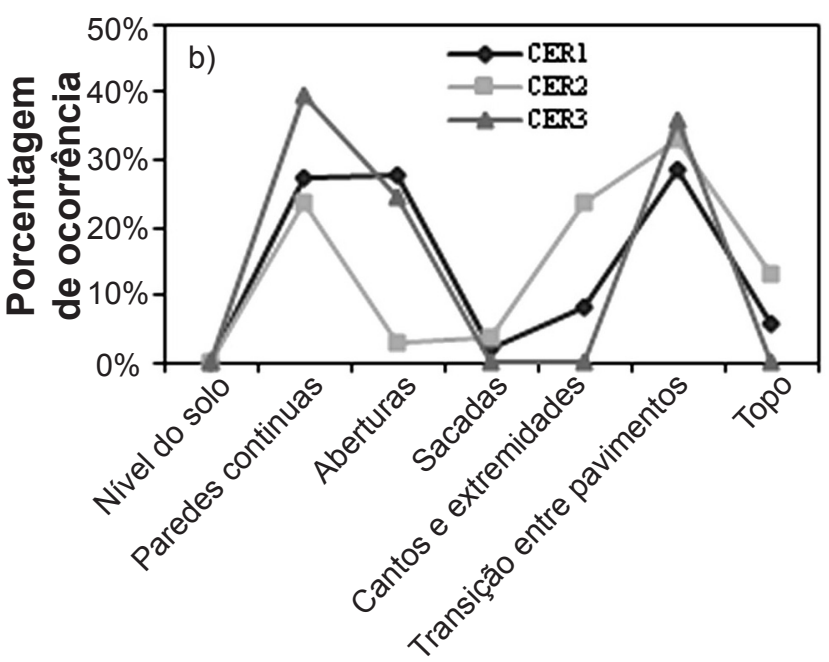

\section{Região da Fachada}

Figura 10: Porcentagem de ocorrência das manifestações patológicas D.p (a) e D.1_a e D.s1 (b) por região de fachada de cada edifício.

[Figure 10: Occurrence percentages of pathological manifestations of the type D.p (a) and the types D.1_a and D.sI (b) in the facade regions of each building.]

resultados corroboraram as regiões de maior ocorrência de D.p, o que indicou que, mesmo não sendo viável a inspeção de todas as regiões, essas três foram as mais incidentes. Já para CER1, apenas a região de aberturas não coincidiu, pois, durante o teste de percussão, não foi possível vistoriar todas as aberturas, o que pode justificar essa diferença. Em CER2, as regiões com maior ocorrência foram as paredes contínuas, cantos e extremidades e transição entre pavimentos, que não foram de acordo com o encontrado em D.p. Essa diferença pode ser associada ao fato da ocorrência de desplacamentos isolados das pastilhas que indicam problemas com a cerâmica que desplacou entre a cerâmica e a argamassa de assentamento.

É válido destacar que uma prática muito comum é a
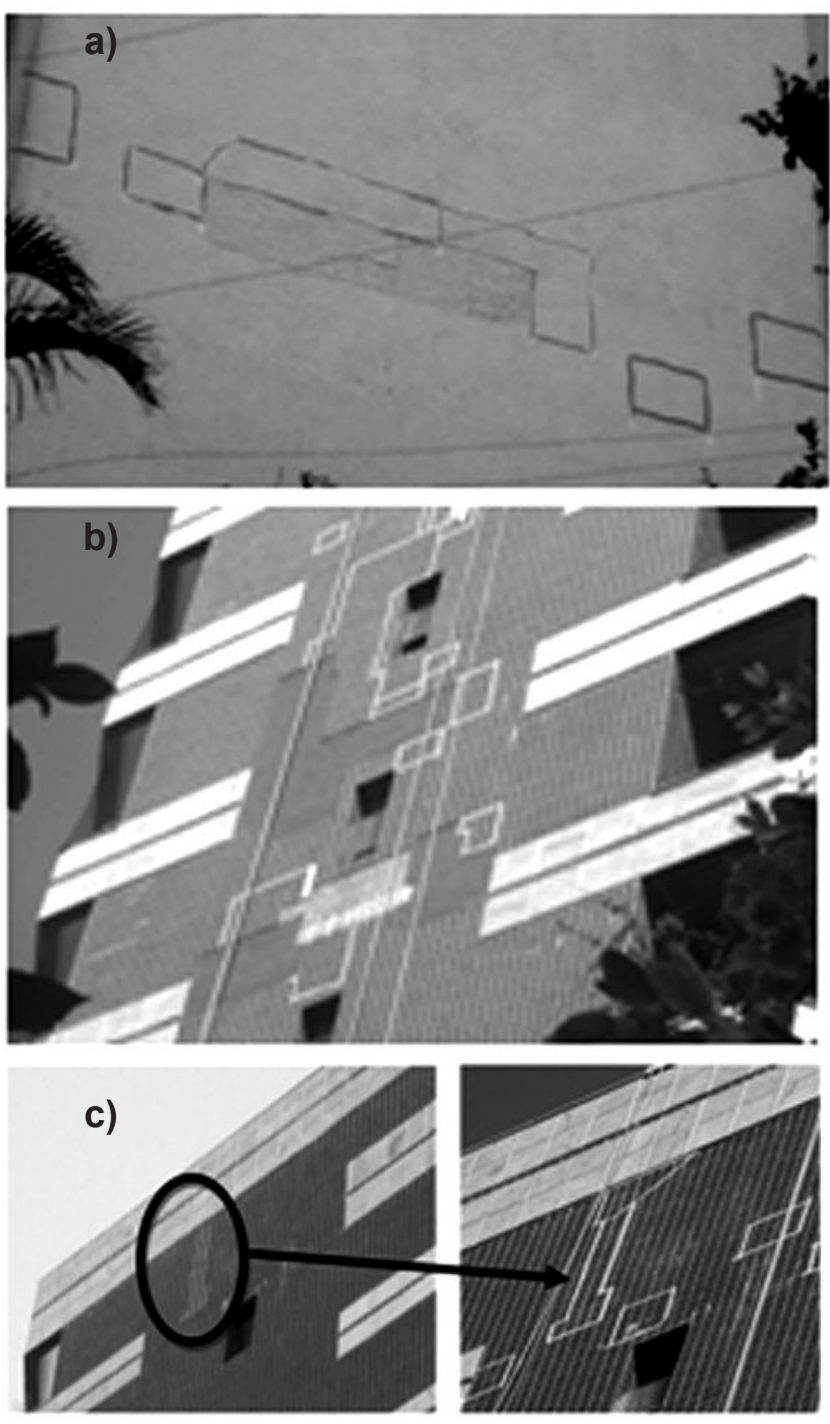

Figura 11: Fotografias mostrando regiões comprometidas no entorno de revestimento já alterado em CER2 (a) e ao redor de revestimentos danificados em CER3 (b); e regiões de D.p no mesmo local em que o revestimento já foi alterado em CER3 (c).

[Figure 11: Photos showing regions committed around coating already replaced in CER2 (a), and around damaged coatings in CER3 (b); and D.p regions in the same place that coating was replaced in $C E R 3$ (c).]

substituição do revestimento que apresenta som cavo apenas nos locais demarcados. Essa medida é eficaz em curto prazo, pois deve ser realizada uma inspeção periódica para constatar mais regiões que estavam em boas condições e começaram a se desprender. Esse exemplo pode ser visualizado na Fig. 11a, na qual se mostra uma região de CER2 em que houve a troca do revestimento. Nessa inspeção, detectou-se que a área no entorno dessa região apresentou som cavo no teste de percussão. Em CER3, a região no entorno de um revestimento retirado se tornou frágil (uma possível área de desplacamento) e isso foi verificado pela marcação das áreas que apresentaram som cavo pelo teste de percussão (Fig. 11b). Outra observação foi uma área em que houve a troca do revestimento cerâmico há uns anos (não especificado 
pela comissão do edifício), na qual novamente foi detectado desplacamento do tipo D.p (Fig. 11c).

\section{Ensaios de absorção de água e expansão por umidade}

Com as cerâmicas retiradas das fachadas, foram realizados os ensaios de absorção de água e expansão por umidade. Os resultados estão resumidos na Tabela VI. Assim, como era previsto, as cerâmicas de CER1 e CER3 apresentaram maior absorção de água em relação às de CER2. Essa característica pode ser atribuída principalmente à superfície lisa do tardoz de CER2. Ao analisar a absorção de água, apenas a cerâmica de CER2 é indicada para fachadas, pois teve índice menor que o recomendado pelo Centro Cerâmico [21], de 6\%, e pela norma britânica BS 5385-2:2015 de 3\% [22]. Com isso, avaliou-se que, durante a especificação dos materiais, não houve correta avaliação das propriedades das cerâmicas. Essa alta absorção facilita a entrada de água através da cerâmica que, ao atingir as camadas de argamassa, gera a fadiga do revestimento por meio da ocorrência das movimentações de expansão e contração do revestimento ocasionada pelos ciclos de secagem e umedecimento do revestimento. Em ambientes com variações de umidade e temperatura, como nas fachadas, essa absorção de água elevada (relacionada com a alta porosidade do material) pode levar ao desplacamento cerâmico, quebra ou até a fissuração do revestimento. Assim, pôde-se relacionar que uma das causas do desplacamento cerâmico em CER1 e CER3 foi a alta absorção de água das placas cerâmicas estudadas.

Com relação à expansão por umidade (EU), essa propriedade física, de acordo com a norma brasileira ABNT NBR 13818:1997 [18], é a principal para análise em cerâmicas que são utilizadas em fachadas. Isso ocorre porque no revestimento externo as placas estão expostas diretamente às intempéries e assentadas em um pano único. A expansão por umidade é decorrente da absorção de água da placa cerâmica oriunda das chuvas e da umidade relativa do ar com as movimentações geradas pela variação da temperatura [23]. Assim, uma expansão acima do limite pode gerar tensões maiores e provocar o desplacamento quando "a placa cerâmica perde a capacidade de resistência existente entre as camadas do sistema revestimento cerâmico" [24]. Outra manifestação patológica associada a essa propriedade é o gretamento que ocorre, entre outros fatores, quando o esmalte da placa cerâmica não acompanha a movimentação da base ocasionada pela

Tabela VI - Resultados dos ensaios de absorção de água e expansão por umidade (EU).

[Table VI - Results of water absorption and expansion by moisture (EU) tests.]

\begin{tabular}{ccc}
\hline Edifício & Absorção $(\%)$ & EU $(\mathrm{mm} / \mathrm{m})$ \\
\hline CER1 & 9,1 & 0,15 \\
CER2 & 0,1 & 0,49 \\
CER3 & 7,4 & 0,25 \\
\hline
\end{tabular}

expansão por umidade [24]. Os resultados das cerâmicas dos três edifícios foram abaixo do limite estabelecido pela norma, de $0,6 \mathrm{~mm} / \mathrm{m}$, e, portanto, estão apropriadas para o uso em fachadas (por esse parâmetro). Porém, é importante destacar que a metodologia de ensaio prescrita na norma é questionada por alguns pesquisadores que afirmam que pelo método da fervura a EU é menor do que a de fato ocorre na fachada $[25,26]$. Com isso, os resultados obtidos nesse ensaio, se fossem realizados por outro método, poderiam ser maiores. Sendo assim, a expansão por umidade pode ter sido uma das causas do gretamento e do desplacamento das placas cerâmicas, mesmo com valor inferior ao exigido pela norma. O gretamento das placas, apesar de pouco observado nos edifícios durante as vistorias, pode estar presente em uma área maior. Isso porque nas cerâmicas de CER1 e CER2 utilizadas para realizar os ensaios de laboratório, após a limpeza da superfície, o gretamento do esmalte ficou acentuado. Ou seja, a sujeira superficial das placas amenizou a visibilidade do gretamento.

\section{Matriz de correlação anomalias x causas prováveis}

Após a avaliação das manifestações patológicas, foi elaborada a matriz de correlação apresentada na Tabela VII. Ao analisar verticalmente a matriz, observam-se as manifestações patológicas que possuem mais causas associadas.Constatou-se que o descolamento do revestimento cerâmico para os três edifícios foi o que possuiu mais causas relacionadas e oriundas de todas as etapas. Com isso, ressaltase a importância do acompanhamento técnico durante a especificação, execução, uso e manutenção desse tipo de revestimento, principalmente devido aos danos ocasionados com a queda do revestimento. Para as manifestações patológicas de deterioração das placas cerâmicas (Dt.l), as causas foram associadas apenas ao uso e à manutenção. Já a deterioração nas juntas (Dt.j) e as anomalias de ordem estética (E.s2, E.s3 e M) foram associadas às causas de todas as etapas; com isso, apesar de aparentemente serem manifestações patológicas com menor risco, precisam de cuidado e acompanhamento específico. A ausência de planeza no revestimento (Es.1) foi uma particularidade, pois foi relacionada apenas à má execução no assentamento das cerâmicas. Para a desagregação do concreto e a corrosão, por se tratarem de manifestações patológicas estruturais, as causas não foram todas especificadas, e relacionou-se apenas a ausência de manutenção.

Para a análise no sentido horizontal da matriz de correlação, avaliam-se as causas mais recorrentes. Observou-se que as provenientes das ações externas, como ações do vento, sol, choque térmico, entre outras, foram as que geraram maior degradação no revestimento cerâmico. Essas análises corroboraram os resultados obtidos em [8]. Essas ações externas não podem ser exterminadas, mas devem ser analisadas para definir a melhor escolha dos materiais, como as argamassas de assentamento, as cerâmicas, os rejuntes e o material de preenchimento das juntas, de forma que minimizem a ação direta dessas causas 
Tabela VII - Matriz de correlação: manifestações patológicas versus causas prováveis.

[Table VII - Correlation matrix: pathological manifestations versus probable causes.]

\begin{tabular}{|c|c|c|c|c|c|c|c|c|c|c|c|c|}
\hline & \multirow{2}{*}{$\begin{array}{l}\text { Dano/ } \\
\text { causa }\end{array}$} & \multirow{2}{*}{$\begin{array}{c}\text { D.1_a } \\
\text { D.s1 } \\
\text { D.p }\end{array}$} & \multirow{2}{*}{$\begin{array}{l}\text { F.s1 } \\
\text { F.s3 }\end{array}$} & \multirow{2}{*}{$\begin{array}{l}\text { Dt.l1 } \\
\text { Dt.l4 }\end{array}$} & \multicolumn{4}{|c|}{ Dt.j } & \multicolumn{3}{|c|}{ E.s } & \multirow{2}{*}{$\mathbf{M}$} \\
\hline & & & & & 1 & 2 & 3 & 5 & 1 & 2 & 3 & \\
\hline \multirow{8}{*}{ 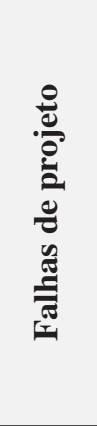 } & A1 & $X$ & $\mathrm{X}$ & & $\mathrm{X}$ & $\mathrm{X}$ & $\mathrm{X}$ & & & $\mathrm{X}$ & $\mathrm{X}$ & \\
\hline & A2 & $X$ & $X$ & & & & $\mathrm{X}$ & & & & & \\
\hline & A3 & $\mathrm{X}$ & & & & & & & & & & \\
\hline & A4 & $X$ & $X$ & & & & $\mathrm{X}$ & & & & $X$ & \\
\hline & A5 & $X$ & & & & $\mathrm{X}$ & & & & & & $X$ \\
\hline & A6 & & & & & $X$ & & & & & & $X$ \\
\hline & A7 & $X$ & & & & & & & & & & \\
\hline & A8 & $X$ & & & & & & $\mathrm{X}$ & & & & \\
\hline \multirow{15}{*}{ 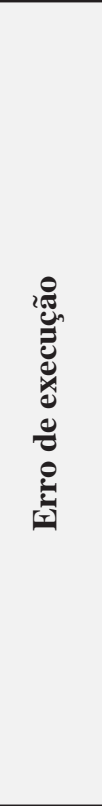 } & B1 & $X$ & $X$ & & $X$ & $X$ & $X$ & & & $X$ & $X$ & \\
\hline & B2 & $X$ & & & & & & & & & & \\
\hline & B3 & $X$ & & & & & & & & & & \\
\hline & B4 & $X$ & & & & & & & & & & \\
\hline & B5 & $X$ & & & & & & & & & & \\
\hline & B6 & $X$ & & & & & & & & & & \\
\hline & B7 & $X$ & & & & & & & & & & \\
\hline & B8 & $X$ & & & & & & & & & & \\
\hline & B9 & & $X$ & & & & $\mathrm{X}$ & & & & & \\
\hline & B10 & $X$ & $X$ & & & & $X$ & & & & $X$ & \\
\hline & B11 & $X$ & $X$ & & & & $X$ & & & & & \\
\hline & B12 & $X$ & & & & $X$ & & & & & & $X$ \\
\hline & B13 & & & & & $X$ & & & & & & $X$ \\
\hline & B14 & $X$ & & & & & & & & & & \\
\hline & B15 & $X$ & & & & & & $\mathrm{X}$ & & & & \\
\hline \multirow{4}{*}{ 递莺 } & $\mathrm{C1}$ & & & $X$ & & & & & & & & \\
\hline & $\mathrm{C} 2$ & & & & & & & & & & & $X$ \\
\hline & C3 & $X$ & $X$ & & & & $X$ & & & & $X$ & \\
\hline & C4 & $X$ & $X$ & & & & $X$ & & & & & \\
\hline \multirow{9}{*}{ 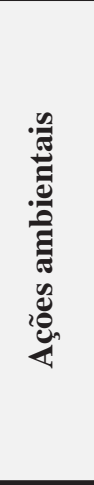 } & D1 & $\mathrm{X}$ & & & & $X$ & & $X$ & & $X$ & & $X$ \\
\hline & D2 & $X$ & & & & $X$ & X & $X$ & & $X$ & & \\
\hline & D3 & $X$ & & & & & $\mathrm{X}$ & & & & $X$ & \\
\hline & D4 & & & & $X$ & & & & & & & \\
\hline & D5 & $X$ & & & $X$ & & & $\mathrm{X}$ & & & & \\
\hline & D6 & & & & & $\mathrm{X}$ & $X$ & $\mathrm{X}$ & & & & \\
\hline & D7 & & & & & $X$ & & & & & & $X$ \\
\hline & D8 & $X$ & $X$ & & & $X$ & $\mathrm{X}$ & & & $\mathrm{X}$ & & \\
\hline & D9 & $X$ & & & & & & & & & $X$ & $X$ \\
\hline \multirow{2}{*}{ 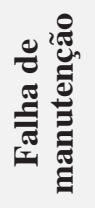 } & E1 & & & & & $X$ & & $X$ & & & & $X$ \\
\hline & E2 & X & $X$ & $X$ & & $X$ & $X$ & & $X$ & $X$ & $X$ & \\
\hline
\end{tabular}


[27]. A análise da orientação cardeal da fachada para avaliar a influência da incidência da chuva e do sol, assim como utilização de elementos arquitetônicos (como coberturas, peitoris e outros), são soluções arquitetônicas que podem ser adotadas para reduzir o impacto das ações externas. As causas associadas aos demais fatores também foram muito incidentes para todas as manifestações patológicas e, com isso, ressalta-se a importância de avaliar e entender todas as etapas de execução e as ações nas quais as fachadas são expostas.

Os três edifícios, por serem antigos, não possuíam as informações relacionadas à especificação dos materiais. Quanto aos que forneceram projetos de fachadas, tratavase apenas da arquitetura com pouco detalhamento e sem especificações de juntas. Com isso, as causas relacionadas ao projeto e à execução podem ser associadas aos dois fatores ou apenas a um deles. Outra informação importante é a ausência de manuais de manutenção, hoje exigidos por norma, mas que, no passado, não eram exigidos e valorizados. Com isso, grande parte das manifestações patológicas foi associada à falta de manutenção e/ou falta de acompanhamento técnico para a execução de reformas.

\section{Considerações sobre os resultados}

Ao ser avaliada a utilização da metodologia proposta, foi possível constatar sua eficiência na inspeção de prédios de diferentes alturas e características arquitetônicas diferentes. Entretanto, foram identificados alguns procedimentos importantes. A lavagem da fachada, antes da inspeção, mostrou-se importante para identificar melhor as manifestações patológicas, como o gretamento e a fissuração das cerâmicas. Porém, antes da lavagem, énecessário vistoriar as fachadas para identificar as manchas e sujeiras presentes. O uso de equipamentos (câmeras de alta resolução, câmeras termográficas e utilização de veículos aéreos não tripulados) pode facilitar o acesso aos locais com maior dificuldade de visibilidade e fornecer mais informações que propiciem um diagnóstico mais preciso. O teste de percussão deve ser realizado imprescindivelmente em todas as fachadas, em edifícios que apresentarem desplacamento. Esse teste mostrou que, relativamente aos edifícios CER1, CER2 e CER3, aparentemente o revestimento estava em bom estado durante a inspeção visual, mas, após o teste, grande parte pode estar comprometida com risco de queda e danos.

Constatou-se que as manchas e sujeiras foram as manifestações patológicas mais recorrentes nos três edifícios, mas possuem baixo nível de degradação. Essas anomalias podem ser solucionadas com a manutenção periódica por meio da limpeza das fachadas, pois são ocasionadas em grande parte pela poluição atmosférica. Os danos nos rejuntes também foram observados em CER2 com a alteração de cor e em CER3 com a fissuração, entre os quais a fissuração no rejunte é a que possui maior nível de degradação (ND=3), e podem facilitar a infiltração da água da chuva aumentando a degradação do revestimento. Com relação ao desplacamento visível, este foi observado nos três edifícios, porém em maior quantidade apenas em CER1. O desplacamento apresenta nível de degradação máximo associado $(\mathrm{ND}=4)$ e, devido a isso, mesmo atingindo pequenas áreas, é um dano que deve ser estudado nos edifícios. Após a constatação desse dano, é preciso realizar o teste de percussão para identificar as áreas que correm risco de queda do revestimento e assim avaliar para entender as causas e propor um reparo imediato.

Este artigo mostrou a utilização dos ensaios de absorção de água e expansão por umidade para complementar os dados obtidos sobre o edifício e ajudar na definição do diagnóstico. Devido à idade dos edifícios, havia ausência de informações sobre o método construtivo e os materiais empregados; em razão disso, esses dois ensaios foram fundamentais para avaliar as cerâmicas utilizadas. Concluiu-se que as cerâmicas dos edifícios CER1 e CER3 não deveriam ser especificadas para utilização em fachadas e a propriedade de alta absorção de água pode ser uma das causas para o desplacamento nesses prédios. Com relação à cor das cerâmicas, as de cor escura apresentaram pior desempenho no teste de percussão. Isso indicou que a cerâmica escura falhou mais rápido que a clara e possuiu maior área com risco iminente de queda.

A orientação cardeal das fachadas apresentou influência nas anomalias relacionadas ao desplacamento cerâmico e, com relação às demais, não houve uma correlação entre a posição e o dano. Observou-se que as fachadas com alta incidência da radiação solar apresentaram pior comportamento nos edifícios CER2 e CER3. Portanto, a influência da radiação solar sobre o revestimento deve ser considerada e analisada, pois, na ausência do sol, o desempenho da fachada é melhor. Entretanto, esperava-se que a fachada norte de CER1 fosse a mais degradada, por apresentar maior incidência solar. Com isso, mais edifícios da cidade de Vitória devem ser avaliados para analisar essa correlação e entender melhor a causa.

A análise da posição das manifestações patológicas com relação às regiões de fachadas foi importante nesses três edifícios, principalmente na análise do desplacamento. Averiguou-se que as regiões de paredes contínuas e transição entre pavimentos foram críticas quanto ao desplacamento. Na parede contínua, devido à sua extensão em relação às demais, já era esperado maior incidência, além de ser uma região de confinamento. Porém, a transição entre pavimentos é uma região pouco extensa com alta incidência dessas anomalias. Ou seja, como não há juntas de movimentação e dessolidarização nas fachadas dos três edifícios, não existem locais apropriados para o alívio de tensões nos revestimentos externos. E a utilização da matriz de correlação para identificar as prováveis causas se mostrou importante ferramenta para identificar a origem dos danos. Constatou-se que o descolamento do revestimento cerâmico foi o que apresentou mais causas associadas, ou seja, tratase de uma anomalia complexa, a qual deve ser estudada melhor, desde a especificação do material até a definição da manutenção. Também foi percebido que as causas provenientes das ações externas (como chuva, sol, variação de temperatura) contribuem para o surgimento e/ou aumento de diversas anomalias. 


\section{CONCLUSÕES}

Avalia-se que a inspeção das fachadas não deve ocorrer apenas visualmente, pois os dados do histórico do edifício, a situação atual do revestimento, os materiais utilizados e as condições de exposição influenciam diretamente no desempenho do revestimento externo. Quanto às fachadas com revestimento cerâmico, o teste de percussão é fundamental para avaliar a degradação real das fachadas, assim como é importante a realização de ensaios complementares nas placas cerâmicas, como a absorção de água e a expansão por umidade. As manifestações patológicas mais incidentes foram as manchas e sujeiras que apresentaram baixo nível de degradação. Também foram observados desplacamento cerâmico e danos nos rejuntes e nas placas. Mediante a análise dos tipos de desplacamento, foi possível constatar a influência da cor da cerâmica e da posição da fachada no desplacamento. Ademais, com a utilização da matriz de correlação, constatou-se a relação entre as ações externas e as manifestações patológicas observadas e o fato de o desplacamento cerâmico possuir causas de diferentes origens associadas, tornando-se um dano que deve ser analisado com maior atenção.

\section{REFERÊNCIAS}

[1] Y.F.M. Moscoso, "Estudo numérico e experimental das tensões atuantes na argamassa colante de fachadas de edificações sob ação da fadiga termomecânica", Diss. Mestr., UnB, Brasília (2013).

[2] A.S. Barbosa, "Estudo numérico-computacional e analítico do choque térmico em fachadas de edificações", Diss. Mestr., UnB, Brasília (2013).

[3] J.G. Uliana, A.F.O. Falcão, R.B. Soares, R.N. Maioli, G.L. Vieira, in $1^{\circ}$ Congr. Bras. Patologia Constr., Foz do Iguaçu (2014).

[4] F.A. Ribeiro, "Especificação de juntas de movimentação em revestimentos cerâmicos de fachadas: levantamento do estado da arte", Diss. Mestr., USP, S. Paulo (2006).

[5] R.M.T. Geyer, "Influência do choque térmico na aderência de azulejos ao substrato", Diss. Mestr., UFRGS, Rio Grande do Sul (1994).

[6] A. Just, "Descolamentos dos revestimentos cerâmicos de fachada na cidade do Recife", Boletim Técn., Univ. S. Paulo, S. Paulo (2001).

[7] A.M.V.A. Chaves, "Patologia e reabilitação de revestimentos de fachadas", Diss. Mestr., Univ. Minho, Portugal (2009).

[8] G.R. Antunes, "Estudo de manifestações patológicas em revestimentos de fachada em Brasília - sistematização da incidência de casos”, Diss. Mestr., UnB, Brasília (2010).

[9] J.F.T. Esquivel, "Avaliação da influência do choque térmico na aderência dos revestimentos de argamassa", Diss. Mestr., USP, S. Paulo (2009).

[10] Inst. Bras. Aval. Pericias Eng., "Norma de inspeção predial nacional", S. Paulo (2012).

[11] L.H. Ceotto, R.C. Nabuk, E.H. Nakakura, "Revestimentos de argamassas: boas práticas em projeto, execução e avaliação", v. 1, ANTAC, Recomendações Técnicas HABITARE, Porto Alegre (2005).

[12] P. Gaspar, J. de Brito, J. Constr. Build. Mater. 19, 8 (2005) 571.

[13] J. Silvestre, J de Brito, "Inspeção e diagnóstico de revestimentos cerâmicos aderentes", Rev. Eng. Civil, Univ. Minho, Portugal (2008).

[14] N.B Lichtenstein, "Patologia das construções: procedimento para diagnóstico e recuperação", BT/PCC/06, S. Paulo (1986).

[15] E.F. Campante, F.H. Sabbatini, "Metodologia de diagnóstico, recuperação e prevenção de manifestações patológicas em revestimentos cerâmicos de fachada", BT/ PCC/301, S. Paulo (2001).

[16] L.E. Guimarães, H. Carasek, O. Cascudo, in Anais VII Congr. Latino Amer. Patologia La Construcción e IX Congr. Control Calidad La Construc., México, Vol. II, Patología, VIII (2003) 9-16.

[17] E. Bauer, E.K. Castro, M.N.B. Silva, Cerâmica 61, 358 (2015) 151.

[18] Assoc. Brasil. Normas Téc., NBR 13818, "Placas cerâmicas para revestimento - especificação e métodos de ensaios" (1997).

[19] D. Trés Junior, "Relatório técnico de inspeção predial ed.”, Parecer Técn., Vitória (2013).

[20] J.C.B Uchôa, "Procedimento numérico e experimental para avaliação da resistência à fadiga de sistemas de revestimento", Diss. Mestr., UnB, Brasília (2007).

[21] Brit. Stand., BS 5385-2, "Wall and floor tiling - part 2: design and installation of external ceramic, natural stone and mosaic wall tiling in normal conditions - code of practice", United Kingdom (2015).

[22] Centro Cerâmico do Brasil, disponível em <http:// www.ccb.org.br/>, acesso em 21 jul. (2016).

[23] S.V.M. Chagas, "Estudo e proposta de um modelo de resistência à fadiga de argamassa de revestimento em estado plano e tridimensional de tensões", Diss. Mestr., UnB, Brasília (2009).

[24] L.M. Pezzato, "Patologias no sistema revestimento cerâmico: um estudo de caso em fachadas", Diss. Mestr., UFSCar, S. Carlos (2010).

[25] R.J.F. Bauer, F. Rago, Cerâm. Ind. 5, 3 (2000) 41.

[26] R.R. Menezes, L.F. Campos, G.A. Neves, H.C. Ferreira, Cerâmica 52, 322 (2006) 114.

[27] J. Silvestre, J. de Brito, Constr. Build. Mater. 25 (2011) 1560 .

(Rec. 23/08/2016, Rev.07/12/2016, Ac. 08/02/2017) 